\title{
Fuzzy Predictive Force Control (FPFC) for Speed Sensorless Control of Single-side Linear Induction Motor
}

\author{
S. Masoumi Kazraji \\ Dept. of Electrical and \\ Computer Engineering \\ University of Tabriz \\ Tabriz, Iran
}

\author{
M. R. Feyzi \\ Dept. of Electrical and \\ Computer Engineering \\ University of Tabriz \\ Tabriz, Iran
}

\author{
M. B. Bannae Sharifian \\ Dept. of Electrical and \\ Computer Engineering \\ University of Tabriz \\ Tabriz, Iran
}

\author{
S. Tohidi \\ Dept. of Electrical and \\ Computer Engineering \\ University of Tabriz \\ Tabriz, Iran
}

\begin{abstract}
In this paper a model fuzzy predictive force control (FPFC) for the speed sensorless control of a single-side linear induction motor (SLIM) is proposed. The main purpose of of predictive control is minimizing the difference between the future output and reference values. This control method has a lower force ripple and a higher convergence speed in comparison to conventional predictive force control (CPFC). In this paper, CPFC and FPFC are applied to a linear induction motor and their results are compared. The results show that this control method has better performance in comparison to the conventional predictive control method.
\end{abstract}

Keywords-linear induction motor(LIM); predictive force control (PFC); fuzzy logic; estimation; speed control

\section{INTRODUCTION}

Linear induction motors (LIMs) have several advantages such as the lack of need of interface mechanical tools, low mechanical losses, high starting force, and simple and strong structure. These motors are widely used in automation systems and industrial applications such as transportation systems, conveyor drives, electromagnetic launchers, and the transfer of containers in container terminals. Among the different linear induction motors, the single-side linear induction motor receives more attention due to its simpler structure and higher endurance $[1,2]$. Linear induction motors receive a lot of attention in transportation systems since they produce direct force without transforming the rotation energy to transition energy. The main characteristics of linear induction motors with electromagnetic excitation in transportation systems include: thrust force, speed, vertical force, efficiency, power factor, and airgap flux density.The appropriate control of characteristics such as force, ripple, and speed convergence of is necessary to obtain a satisfactory operation in transportation systems [3, 4]. Several LIM modeling methods have been proposed. An LIM model based on electrical design with the consideration of the end, the edge, and the skin effects has been investigated in [5]. Usual design parameters can be found in [6] Dynamic LIM models have been investigated in [7-10]. In [7] and [8], a dynamic model based on the structural elements (width and the depth of slots), secondary thickness, and the number of turns is presented. Among the different control methods, Model Predictive Force Control (MPFC) has received increased attention as an effective method [11, 12]. PFC directly predicts the considered variables such as force and stator flux. With the calculation of the effect of each possible voltage vector, a force error and minimum flux is selected as the best voltage vector. Therefore, it is clear that the MPFC selected vector is more precise and more effective in comparison with DFC. In addition, the flexibility of MPFC allows the control to include non-linear factors and to apply the limitations of the control variables.

In MPFC, a cost function is usually defined based on the errors of torque amplitude and flux, but in order to have a satisfactory operation, there is a need for an appropriate weight function. However, tuning the weight function is not easy due to the lack of a theoretical design method. In [13], an empirical method for achieving appropriate weight coefficients has been investigated. In [14], a precise discrete time state-space model for induction motors has been discussed and a current restriction in the cost function has been placed for the prevention of over current. According to [15] and [16], although MPTC acts more precisely and more effectively in selecting the voltage vector (in comparison with DTC), applying the selected voltage vector without the tuning coefficient is not optimum. In DTC, the placement of the zero voltage vector along with the active voltage vector in the control period can help in regulating the voltage appropriately and precisely [17]. In [18], minimizing principles of the torque ripple for the calculation of the optimum weight coefficient have been introduced, but the equation of the optimum weight coefficient is complicated and the parameters depend on each other.

\section{MATHEMATICAL MODEL OF LIM}

In order to obtain the LIM model in a $d-q$ reference frame, first the stator voltage equation should be introduced $[2,10]$ :

$$
u_{d s}=R_{s} i_{d s}+R_{r} f(Q)\left(i_{d s}+i_{d r}\right)+\frac{d}{d t} \psi_{d s}
$$




$$
u_{q s}=R_{s} i_{q s}+\frac{d}{d t} \psi_{q s}
$$

The equations of the secondary voltage in the direction of dq are as follows:

$$
\begin{aligned}
& u_{d r}=R_{r} i_{d r}+\frac{\pi}{\tau} v_{r} \psi_{q r}+R_{r} f(Q)\left(i_{d s}+i_{d r}\right)+\frac{d}{d t} \psi_{d r} \\
& u_{q r}=R_{r} i_{q r}-\frac{\pi}{\tau} v_{r} \psi_{d r}+\frac{d}{d t} \psi_{q r} \\
& f(Q)=\frac{1-e^{-Q}}{Q} \\
& Q=\frac{L_{p} / v_{r}}{\left(L_{m}+L_{r}\right) / R_{r}}
\end{aligned}
$$

where, $\mathrm{R}_{\mathrm{s}}$ and $\mathrm{R}_{\mathrm{r}}, \mathrm{L}_{\mathrm{s}}$ and $\mathrm{L}_{\mathrm{r}}, \mathrm{L}_{\mathrm{p}}$ and $\mathrm{v}_{\mathrm{r}}, \mathrm{p}$ and $\tau$ are primary and secondary resistance, primary and secondary inductances, primary long and linear speed, pole number and pole pitch respectively, and $L_{m}$ is the magnetic inductance. $f(Q)$ has been used to take the end effect of LIM into account in (5). Moreover, $f(Q)$ has been used to provide the end effect on the magnetic factor of LIM in the simulation model.

The vectors of the stator flux and the secondary sheet flux are calculated from the current and the measured inductance in (7)-(10). The equations of the linkage flux are as follows:

$$
\begin{aligned}
& \psi_{d s}=L_{s} i_{d s}+L_{m}(1-f(Q))\left(i_{d s}+i_{d r}\right) \\
& \psi_{q s}=L_{s} i_{q s}+L_{m}\left(i_{q s}+i_{q r}\right) \\
& \psi_{d r}=L_{r} i_{d r}+L_{m}(1-f(Q))\left(i_{d s}+i_{d r}\right) \\
& \psi_{q r}=L_{r} i_{q r}+L_{m}\left(i_{q s}+i_{q r}\right)
\end{aligned}
$$

The electromagnetic force of the LIM is estimated by (11) and then (12) is calculated. The thrust force is calculated as follows:

$$
\begin{aligned}
& F_{e}=\frac{3}{2} \frac{\pi}{\tau} \frac{P}{2}\left(\psi_{d s} i_{q s}-\psi_{q s} i_{d s}\right) \\
& F_{e}=\frac{3}{2} \frac{\pi}{\tau} \frac{P}{2} \frac{L_{m}(1-f(Q))}{L_{r}-L_{m} f(Q)} \\
& \times\left(\psi_{d r} i_{q s}-\frac{L_{r}^{2}}{L_{r}} \frac{f(Q)}{(1-f(Q))} i_{d s} i_{q s}\right)
\end{aligned}
$$

The above equations have been used to simulate LIM.

\section{FUZZY MODEL PREDICTIVE FORCE CONTROL}

The general control diagram for the proposed FPFC is shown in Figure 1. It can be seen that the reference of the force has been produced by an external speed control loop and the reference of the stator flux amplitude has been kept stable since the operation of the flux weakening has not been considered in this paper. The information and the details about this control diagram are provided below.

\section{A. Estimation of the Flux and Force}

The precise estimation of flux and force is essential for the satisfactory operation of the FPFC. In this paper, a full-order observer has been applied at low speed range due to high precision. The precision of the estimation and the robustness of the observer are increased against the changes of the motor parameters with the introduction of stator current error feedback. The mathematical model of the observer based on the LIM model in (1) is:

$$
\frac{d \hat{x}}{d t}=A \hat{x}+B u+G\left(i_{s}-\hat{i}_{s}\right)
$$

In the above equation, $\hat{x}=\left[\begin{array}{ll}\hat{i}_{s} & \hat{\psi}_{s}\end{array}\right]^{T}$ are the variables of the estimation state.

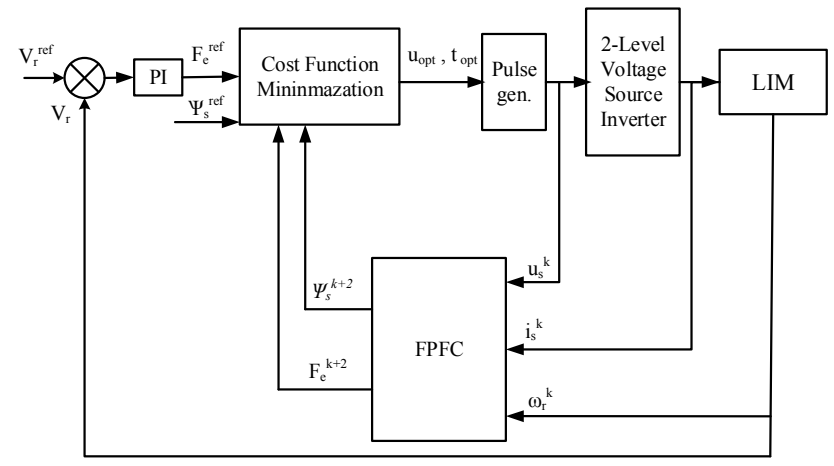

Fig. 1. Control diagram of the FPFC.

$$
G=-\left[\begin{array}{c}
2 b \\
b / \lambda L_{r}
\end{array}\right]
$$

In the above equation $\lambda=\frac{1}{\left(L_{s} L_{r}-L_{m}^{2}\right)}$ and $\mathrm{b}$ is the negative stable gain. This method of displacing the poles increases the convergence and the stability of the observer especially at low speeds and it is easy to be applied.

\section{B. Fuzzy Logic Control}

Fuzzy logic controller is suitable especially for complex or nonlinear systems. Figure 2 shows the structure of the fuzzy controller used in this paper. Asshown, the inputs of the fuzzy controller are the error signal and its derivative and the output is the reference value which is applied to the system. The input and output membership functions are normalized values. Thus, determining correct values for $\mathrm{K}_{1}, \mathrm{~K}_{2}$ and $\mathrm{K}_{3}$ is essential. Figure 3 shows a three dimension inputs-output diagram. In this paper, the triangular membership function is used due to its simplicity and efficiency [19]. 


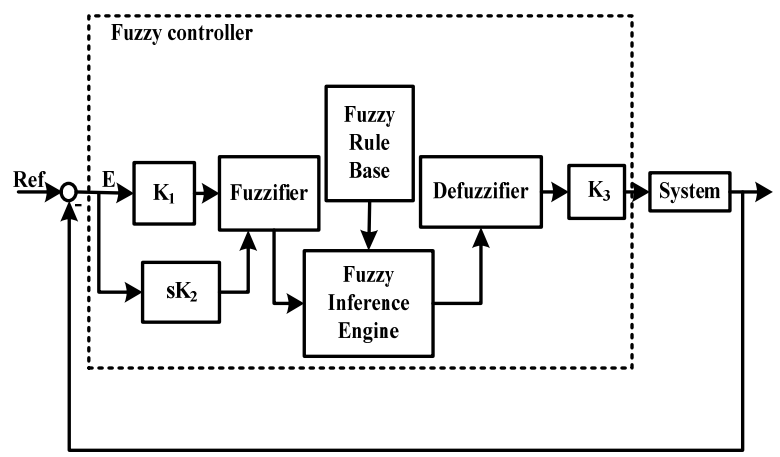

Fig. 2. The structure of the fuzzy controller.

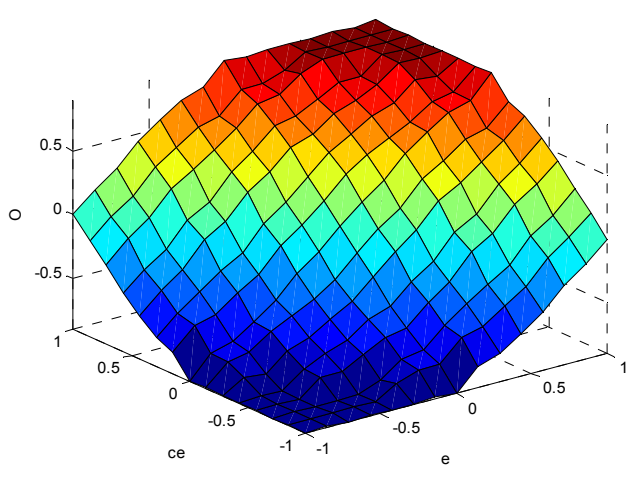

Fig. 3. Three dimension inputs-output diagram

\section{The Selection of the Vector}

In the conventional MPFCs [20], the stator flux and the electromagnetic force have been predicted as the primary states by the predictive model with $\mathrm{i}_{\mathrm{s}}(\mathrm{k})$ and $\psi_{\mathrm{s}}(\mathrm{k})$ variables at the moment of $k+1$. The aim is to make the stator flux and the force follow their references. In other words, the error between the estimated flux and force with their reference values has to be minimized. This takes the form of a cost function which is provided as follows:

$$
\begin{aligned}
J & =\left|F_{e}^{r e f}-\hat{F}_{e}(k+1)_{i}\right|+k_{\psi}|| \psi_{s}^{r e f}|-| \hat{\psi}_{s}(k+1)_{i}|| \\
& i \in\{1,2,3,4\}
\end{aligned}
$$

In the proposed FPFC, in order to determine the sign of the force and the stator flux, a weight coefficient of the stator flux, $\mathrm{k}_{\psi}$ is selected as follows:

$$
k_{\psi}=\frac{F_{n}}{\psi_{s n}}
$$

In the above equation, $F_{n}$ is the nominal force, and $\psi_{\mathrm{sn}}$ is the stator flux amplitude. It should be noted that the $\mathrm{k}_{\psi}$ weight coefficient in (16) is only used as a starting point for tuning and the final practical amount of $\mathrm{k}_{\psi}$ is larger than (16), which was shown in [21]. The current of the stator is not directly used in the conventional MPFC cost function. The prediction of stator current is eliminated in order to decrease the complexity. To predict the force at the $\mathrm{k}+1$ th moment without the prediction of the stator current, the following equations are employed:

$$
\begin{aligned}
& F_{e}(k+1)=\frac{3}{2} \frac{\pi}{\tau} \frac{p}{2} \psi_{s}(k=1) \otimes i_{s \lambda}(k) \\
& i_{s \psi}(k)=\left(1-\lambda R_{r} L_{s} F_{s c}+j \omega_{r} F_{s c}\right) i_{s}(k) \\
& +\lambda\left(R_{r} F_{s c}-L_{r}-j \omega_{r} L_{r} F_{s c}\right) \psi_{s}(k)
\end{aligned}
$$

In the above equations, $\mathrm{i}_{\mathrm{s} \lambda}(\mathrm{k})$ has been calculated based on the variables of the kth moment.

\section{SIMULATION AND EXPERIMENTAL RESULTS}

\section{A. Simulation Results}

The simulation was conducted in MATLAB/Simulink. The results of [22] have been used for comparison. The flowchart of the algorithm is shown in Figure 4. The parameters are provided in Table I. The reference of the stator flux is $0.9 \mathrm{~Wb}$, which is lower than the nominal amount in order to prevent saturation. The $\mathrm{k}_{\psi}$ weight coefficient in the weight function is only used to regulate the parameters of FPFC. The tuning has been carried for the selection of the most appropriate $k_{\psi}$. However, the selection of a weight coefficient is still a new issue and is usually determined intuitively [22]. The final amount of the $k_{\psi}$ weight coefficient is 50 in this paper, which has been applied based on a comprehensive simulation.

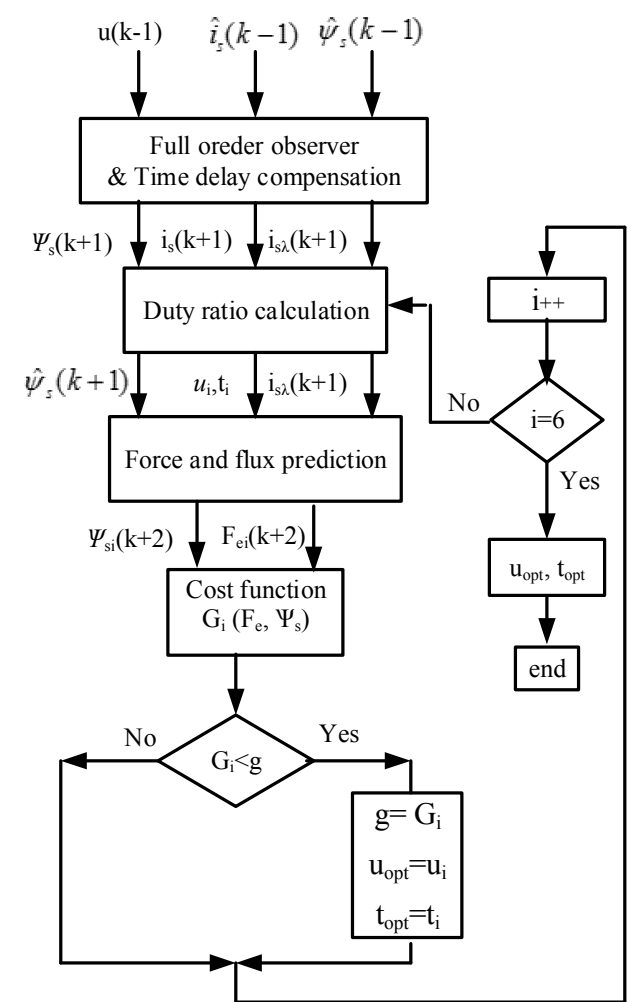

Fig. 4. Flowchart of the proposed MPFC method with the consideration of time-delay 
Figure 5 shows the responses of the steady state simulation at step-function speed of 1.5 to $0.4 \mathrm{~m} / \mathrm{s}$, with rated load of $50 \mathrm{~N}$ for CPFC, FPFC. From top to the bottom, the curves in Figure 5 show (a) the electromagnetic force, (b) the amplitude of the stator flux and (c) the one phase stator current for $\mathrm{CPFC}$ and FPFC respectively. It can be seen that CPFC has a relatively large force ripple and large current harmonics in comparison with FPFC. In CPFC the unregulated force ripple appears in the stator flux. This issue emerges because the selected voltage vector is not long-lasting when determined proportionally to a separate duty. The proposed FPFC provides a more stable operation in terms of force ripple, flux and harmonics of stator current which confirms the positive effect of the tuning coefficient.

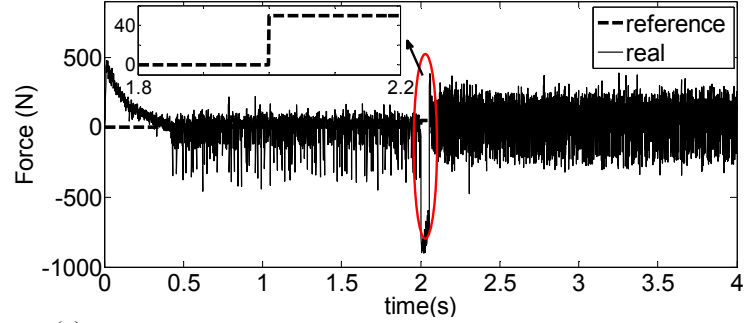

(a)

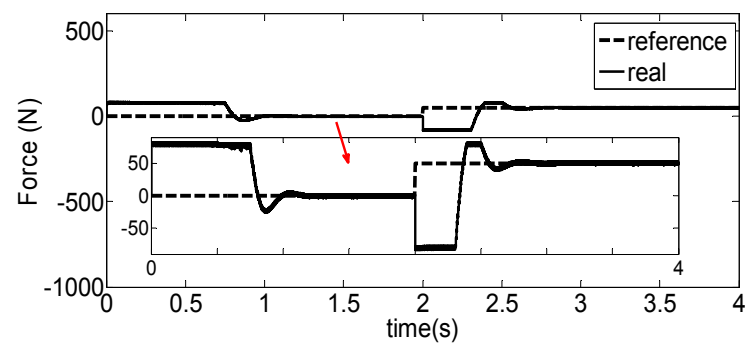

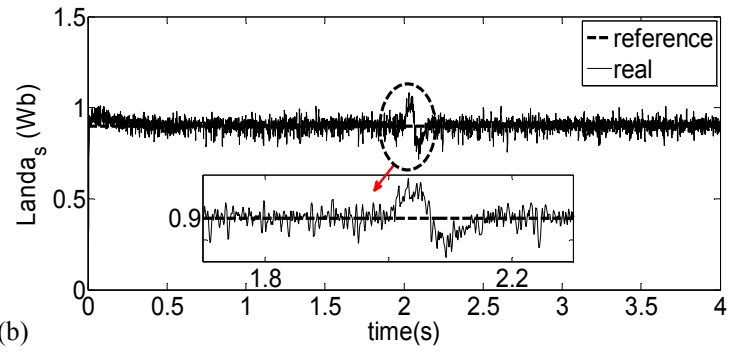

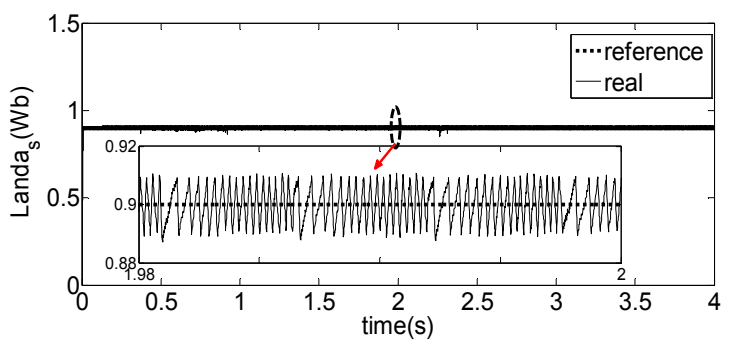

(c)
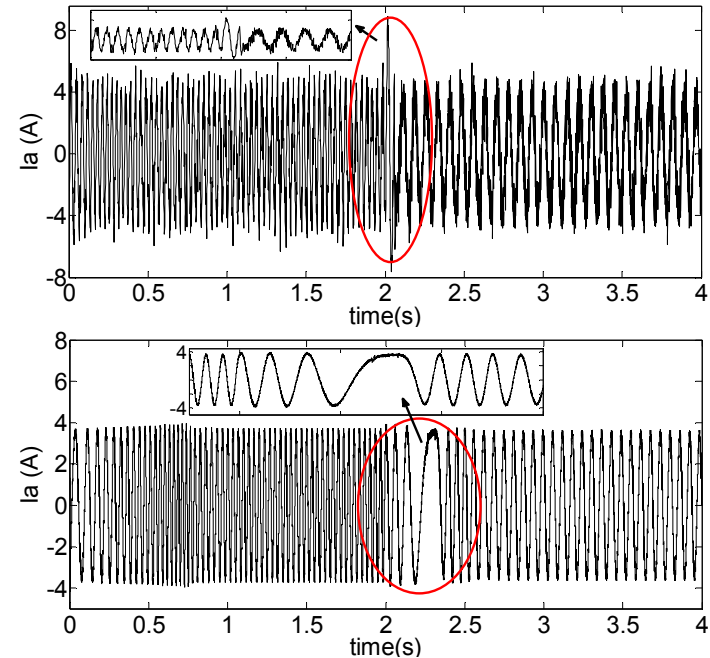

Fig. 5. The responses of the steady state simulation at step-function speed of 1.5 to $0.4 \mathrm{~m} / \mathrm{s}$, with rated load for CPFC and FPFC respectively: (a) electromagnetic force, (b) stator flux, (c) phase current

The stable states responses, at the speed in which they are higher than the nominal load, are shown in Figure 6. It can be seen that the FPFC shows a better operation in force ripple and flux and has fewer current harmonics. Figures 7 and 8 show motor speed response waveform, for CPFC and FPFC, in high and low speeds. It is seen that in the FPFC method, the response speed of the motor has a shorter rise time than the CPFC. As shown, FPFC method can be adapted over the reference value in less time than $\mathrm{CPFC}$, which is a confirmation of the proper operation of the proposed MPFC method.

\section{B. Experimental Results}

Real-time hardware-in-the-loop (HIL) simulation is an effectual technique for advanced measurements that provides a link between simulation and real conditions. In the HIL simulation, real hardware of the investigated system is not accessible and thus emulated hardware is employed. 
TABLE I. LIM AND INVERTER PARAMETERS

\begin{tabular}{|c|c|}
\hline Parameter & Values \\
\hline Linear Induction Motor & ----- \\
\hline Rated power & $8.5 \mathrm{~kW}$ \\
\hline Rated voltage & $290 \mathrm{v}$ \\
\hline Rated speed & $5 \mathrm{~m} / \mathrm{s}$ \\
\hline Rated curren & $4.8 \mathrm{~A}$ \\
\hline Pole pairs & 3 \\
\hline Primary leakage inductance $\left(\mathrm{L}_{\mathrm{ls}}\right)$ & $69 \mathrm{mH}$ \\
\hline Secondary leakage inductance $\left(\mathrm{L}_{\mathrm{lr}}\right)$ & $\approx 0 \mathrm{mH}$ \\
\hline Magnetizing resistance $\left(\mathrm{L}_{\mathrm{m}}\right)$ & $200 \mathrm{mH}$ \\
\hline Primary resistance $\left(\mathrm{R}_{\mathrm{s}}\right)$ & $10.6 \Omega$ \\
\hline Secondary resistance $\left(\mathrm{R}_{\mathrm{r}}\right)$ & $30 \Omega$ \\
\hline Moving mass $(\mathrm{M})$ & $20 \mathrm{~kg}$ \\
\hline Inverter & ----- \\
\hline DC-link voltage $(\mathrm{U})$ & $460 \mathrm{v}$ \\
\hline
\end{tabular}
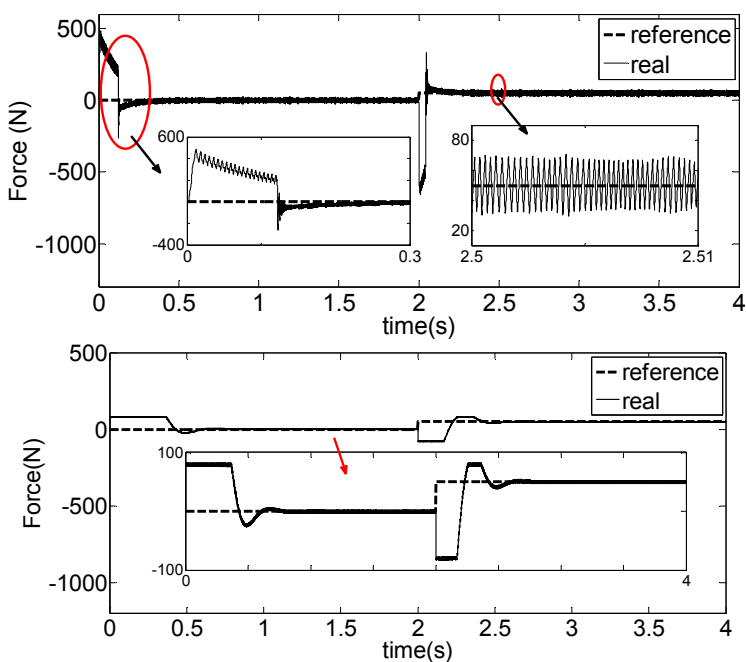

(a)
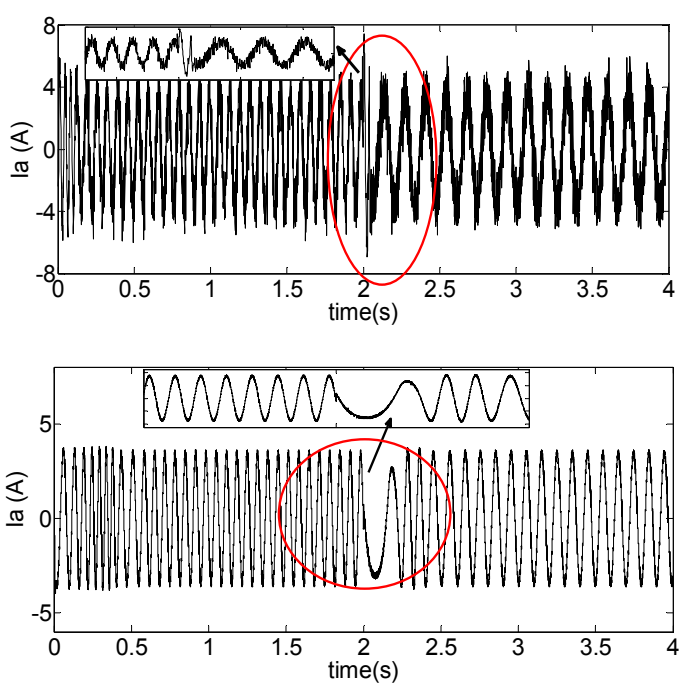

(b)

Fig. 6. The responses of the steady state simulation at step-function speed of 6 to $1 \mathrm{~m} / \mathrm{s}$, with rated load for CPFC and FPFC respectively: (a) electromagnetic force, (b) phase current
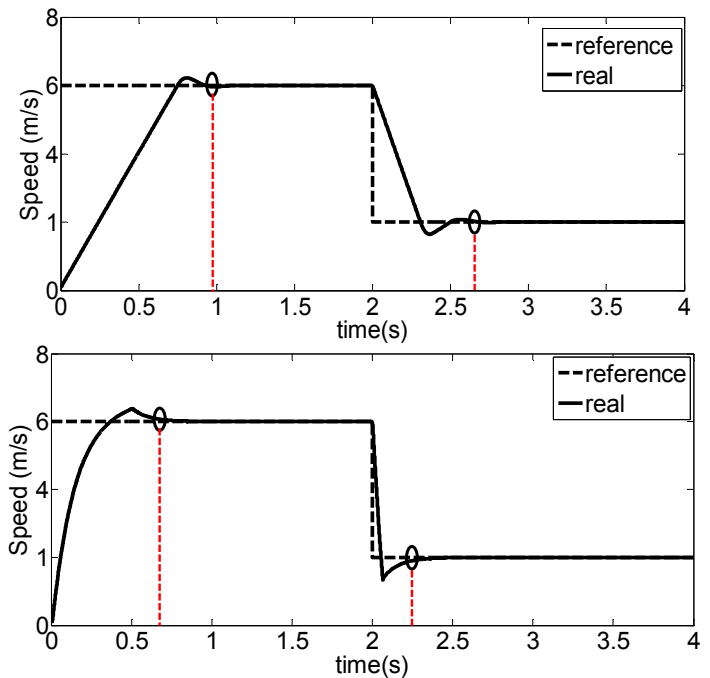

Fig. 7. The response speed of the motor, for CPFC and FPFC respectively, in high speed.
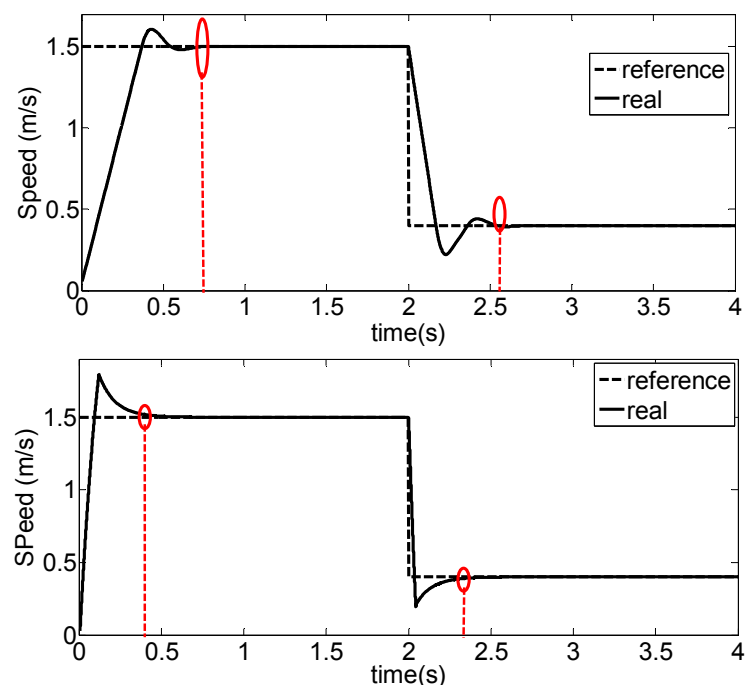

Fig. 8. The response speed of the motor, for CPFC and FPFC respectively, in low speed.

In order to get a real-time based HIL simulation, the MATLAB/Real-time windows target toolbox was employed and the performance of the proposed FPFC of the LIM was clarified using the approach in $[23,24]$. Figures 9(a) and 9(b) show the illustrative diagram and experimental layout of the real-time HIL method. The vector control scheme with speed estimator is employed on an ezdspF2812 board. The LIM dynamic model and the nonlinear inverter model described in [10], were simulated on a host PC. Thus, the host PC is employed as a LIM and inverter emulator. The real-time control commands of the DSP board are applied to the host PC as digital control signals using an Advantech PCI 1711 card located on PC bus. The analog/digital feedback signals are returned to the DSP board and subsequently processed to get control commands. Furthermore, an interface board is employed for sending data from the DSP board to the 
oscilloscope. In fact, in the experimental testing, the host PC (LIM emulator) is switched with the LIM and inverter board. Therefore, the real-time property of experimental testing is maintained. Figures 10 and 11, show the results from the realtime HIL method for motor speed response waveform, for CPFC, FPFC, in high and low speeds. It is seen that in the FPFC method, the response speed of the motor has a shorter rise time than the CPFC. FPFC method can be adapted in less time than the other methods over the reference value, which is a confirmation of the proper operation of the proposed FPFC. Figure 12 demonstrates the results from the real-time HIL method for electromagnetic force, for methods CPFC and FPFC. It can be seen that $\mathrm{CPFC}$ has a relatively large force ripple and large current harmonics in comparison to FPFC. The proposed FPFC shows the most stable operation in the force ripple which confirms the effect of tuning coefficient during the selection of the best vector.

(a)

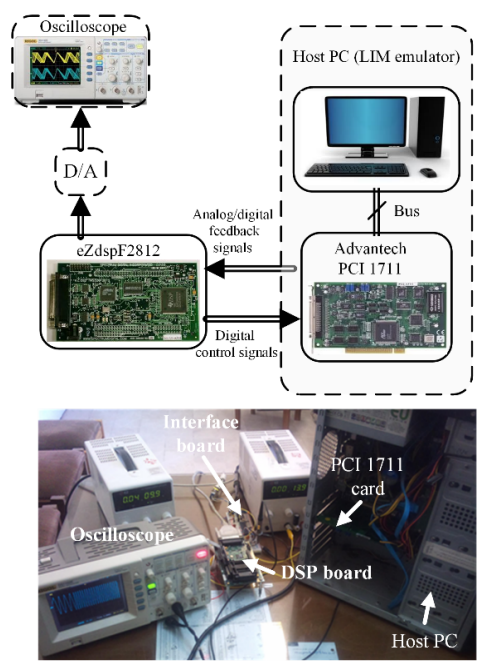

Fig. 9. Real-time HIL structure (a) schematic diagram (b) experimental layout.
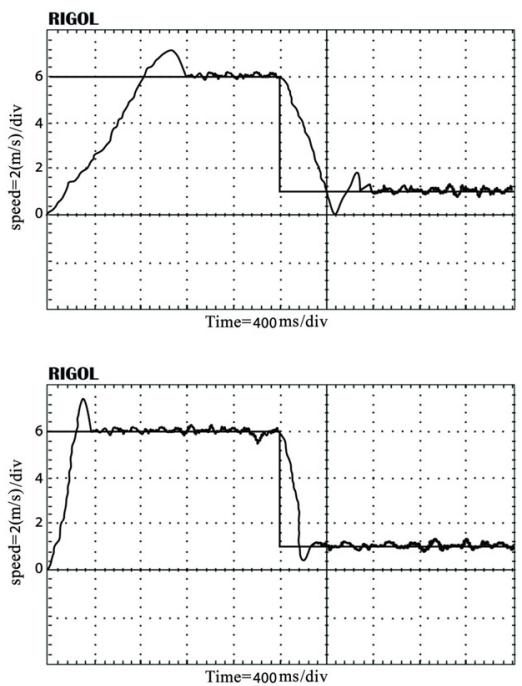

Fig. 10. The response speed of the motor in high speed, for CPFC and MPFC respectively, (HIL method).
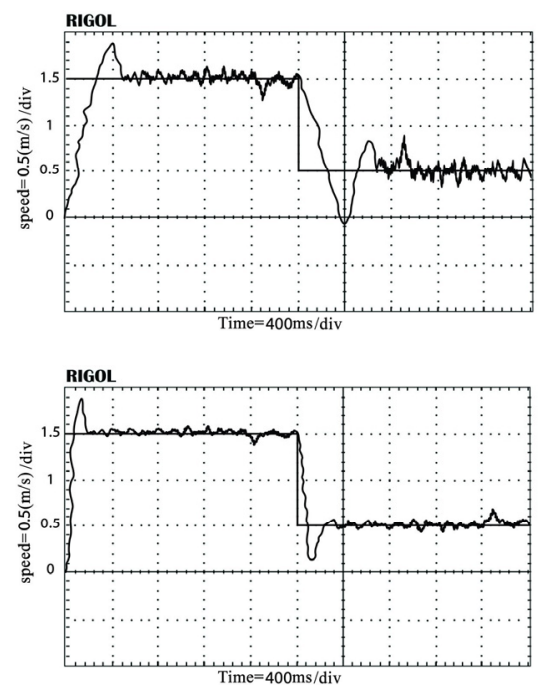

Fig. 11. The motor response speed, for CPFC and FPFC respectively in low speed (HIL method)
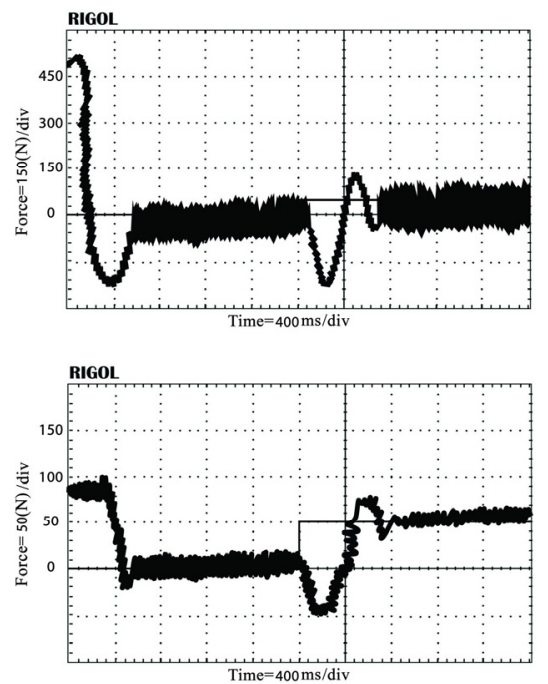

Fig. 12. The response electromagnetic force of the motor, for CPFC and FPFC II respectively, in high speed (HIL method)

\section{CONCLUSION}

The conventional PFC has a relatively high force ripple due to the limited number of voltage vectors in the two-level invertor and the lack of tuning flux coefficient in the stable state. In order to decrease force ripple, the tuning coefficient of the flux in FPFC for the linear induction motor has been used in low speed systems. In the optimized FPFC, the voltage vector is selected first based on the minimizing of the weight function and then the selected vector is calculated. From the aspect of error minimizing of the thrust force and flux, a better methodology was proposed. Simulation and experimental tests were used to validate the proposed methodology. A comparative investigation was carried out between the proposed FPFC and the CPFC. In the proposed method, an 
improved operation of force and flux can be seen at different speeds, with or without load force, especially within the low speed range. In the meantime, the fast dynamic response in the $\mathrm{CPFC}$ has been maintained.

\section{REFERENCES}

[1] I. Boldea, S. A Nasar, "Linear electric actuators and generators", IEEE International Conference on Electric Machines and Drives Record, pp. MA1/1.1-MA1/1.5, 1997

[2] I. Boldea, Linear electric machines, drives, and maglevs handbook, CRC Press, 2013

[3] R. Hellinger, P. Mnich, "Linear Motor-Powered Transportation: History, Present Status, and Future Outlook," Proceedings of the IEEE, Vol. 97, No. 11, pp. 1892-1900, 2009

[4] L. Yan, "The Linear Motor Powered Transportation Development and Application in China," Proceedings of the IEEE, Vol. 97, No. 11, pp. 1872-1880, 2009

[5] I. Boldea, S. A. Nasar, Linear Electric Actuators and Generators, Cambridge, U.K.: Cambridge University Press, 1997

[6] I. Boldea, S. A. Nasar, Linear Electric Motors, Englewood Cliffs, NJ, USA: Prentice-Hall, 1987

[7] F. Alonge, M. Cirrincione, M. Pucci, A. Sferlazza, "Input-output feedback linearizing control of linear induction motor taking into consideration the end-effects. Part I: Theoretical analysis", Control Engineering Practice, Vol. 36, pp. 133-141, 2015

[8] F. Alonge, M. Cirrincione, M. Pucci, A. Sferlazza, "Input-output feedback linearizing control of linear induction motor taking into consideration the end-effects. Part II: Simulation and experimental results", Control Engineering Practice, Vol. 36, pp. 142-150, 2015

[9] T. T. Overboom, J. P. C. Smeets, J. W. Jansen, E. Lomonova, "Decoupled control of thrust and normal force in a double-layer singlesided linear induction motor", Mechatronics, Vol. 23, No. 2, pp. $213-$ 221,2013

[10] G. Kang, K. Nam, "Field-oriented control scheme for linear induction motor with the end effect", IEE Proceedings - Electric Power Applications, Vol. 152, No. 6, pp. 1565-1572, 2005

[11] S. Masoumi Kazraji, M. B. Bannae Sharifian, "Direct Thrust Force and Flux Control of a PM-Linear Synchronous Motor Using Fuzzy SlidingMode Observer", Advances in Electrical and Electronic Engineering, Vol. 13, No.1, pp. 1-9, 2015

[12] C. A. Rojas, J. Rodriguez, F. Villarroel, J. R. Espinoza, C. A. Silva, M. Trincado, "Predictive torque and flux control without weighting factors", IEEE Transactions on Industrial Electronics, Vol. 60, No. 2, pp. 681690,2013

[13] Y. Zhang, W. Xie, Z. Li, Y. Zhang, "Model predictive direct power control of a PWM rectifier with duty cycle optimization", IEEE Transactions on Power Electronics, Vol. 28, No. 11, pp. 5343-5351, 2013

[14] S. A. Davari, D. A. Khaburi, R. Kennel, "An improved FCS-MPC algorithm for an induction motor with an imposed optimized weighting factor", IEEE Transactions on Power Electronics, Vol. 27, No. 3, pp. 1540-1551, 2012

[15] C. A. Rojas, J. Rodriguez, F. Villarroel, J. R. Espinoza, C. A. Silva, M Trincado, "Predictive torque and flux control without weighting factors", IEEE Transactions on Industrial Electronics, Vol. 60, No. 2, pp. 681690,2013

[16] T. Geyer, "Computationally efficient model predictive direct torque control", IEEE Transactions on Power Electronics, Vol. 26, No. 10, pp. 2804-2816, 2011

[17] S. A. Davari, D. A. Khaburi, R. Kennel, "An improved FCS-MPC algorithm for an induction motor with an imposed optimized weighting factor", IEEE Transactions on Power Electronics, Vol. 27, No. 3, pp. $1540-1551,2012$
[18] Y. Zhang, H. Yang, "Torque ripple reduction of model predictive torque control of induction motor drives", IEEE Energy Conversion Congress and Exposition, pp. 1176-1183, 2013

[19] M. Hosein Holakooie, M. Ojaghi, A. Taheri, "Full-order Luenberge observer based on fuzzy-logic control for sensorless field-oriented control of a single-sided linear induction motor", ISA Transactions, Vol. 60, pp. 96-108, 2016

[20] J. Rodriguez, P. Cortes, Predictive Control of Power Converters and Electrical Drives, New York, , USA: Wiley-IEEE Press, 2012

[21] C. Lascu, A. Trzynadlowski, "Combining the principles of sliding mode, direct torque control, and space vector modulation in a high performance sensorless ac drive", IEEE Transactions on Industry Applications, Vol. 40, No. 1, pp. 170-177, 2004

[22] H. Miranda, P. Cortes, J. I. Yuz, J. Rodriguez, "Predictive torque control of induction machines based on state-space models IEEE Transactions on Industrial Electronics, Vol. 56, No. 6, pp. 1916-1924, 2009

[23] J. H. Jung, "Real-time and Power Hardware-in-the-loop Simulation of PEM Fuel Cell Stack System", Journal of Power Electronics, Vol. 11, No. 2, pp. 202-210, 2011

[24] C. S. Edrington, O. Vodyakho, B. A. Hacker, "Development of a Unified Research Platform for Plug-In Hybrid Electrical Vehicle Integration Analysis Utilizing the Power Hardware-in-the-Loop Concept", Journal of Power Electronics, Vol. 11, No. 4, pp. 471-478, 2011

\section{AUTHORS PROFILE}

Saeed MASOUMI KAZRAJI was born in Tehran, Iran in 1989. He received the B.Sc. degree from the Sbzevar University of Tarbiat Moallem, Mashhad, Iran in 2011 and the M.Sc. degree from University of Tabriz, Tabriz, Iran in 2013, both in Electrical Power Engineering. He is currently pursuing the Ph.D. program at the Universityof Tabriz. His research interests include drive and motion control of electric machines, machine design and power electronic converters.

Mohammad Reza FEYZI received the B.Sc. (Hons.) and M.Sc. (Hons.) degrees in electrical engineering from the University of Tabriz, Tabriz, Iran, in 1973 and 1975, respectively., and the Ph.D. degree in electrical engineering from the University of Adelaide, Adelaide, Australia in 1997. He worked with the University of Tabriz from 1975 to 1993. Soon after his graduation from the University of Adelaide, he resumed working at the University of Tabriz, where he is currently a Professor at the Department of Power Engineering. He is proficient in using two commercial finite elements softwares, such as "ANSYS" and "VectorFields." His research interests are design, and analysis of electrical machines using finite element methods.

Mohammad Bagher BANNAE SHARIFIAN studied Electrical Power Engineering at the University of Tabriz, Tabriz, Iran. He received the B.Sc. and M.Sc. degrees in 1989 and 1992 respectively from the University of Tabriz. In 1992 he joined the Electrical Engineering Department of the University of Tabriz as a lecturer. He received the Ph.D. degree in Electrical Engineering from the same University in 2000. In 2000 he rejoined the Electrical Power Department of the Faculty of Electrical and Computer Engineering of the same university as an Assistant Professor. He is currently a Professor of the mentioned Department. His research interests are in the areas of design, modeling and analysis of electrical machines, transformers, linear electric motors, and electric and hybrid electric vehicle drives.

Sajjad TOHIDI was born in Meshkin Shahr, Iran, in 1984. He received the B.Sc. degree from Iran University of Science and Technology, Tehran, Iran, in 2006, and M.Sc. and Ph.D degree in 2008 and 2012 respectively from Sharif University of Technology (SUT), Tehran, Iran. He was on sabbatical at Durham University, Durham, U.K., and University of Cambridge, Cambridge, U.K., in 2011. He is currently an Assistant Professor in the Department of Power Engineering of the University of Tabriz. His research interests include power systems dynamics, electrical machines, and wind power generation. 